\section{On the beach}

Donald J.P. Swift

The Morphodynamics of the Wadden Sea. By Jürgen Ehlers. A.A. Balkema: 1988. Pp.397. DM 185, £52. 75.

THE Wadden Sea is the intertidal zone of the German Bight of the North Sea. Varying in width from 10 to $50 \mathrm{~km}$, it is an expanse of tidal channels, flats, inlets, flood and ebb deltas, barrier islands and estuaries that extends from Den Helder in the Netherlands to Blåvandshuk in Denmark.

Jürgen Ehlers explains that while mapping the geomorphology of the Wangerooge (map) sheet, "I came to realize the importance of both the major and minor bedforms of the Wadden Sea.... At the same time, my observations led me to suspect that the remodeling of the landscape [was occurring] at a much faster rate than I had previously assumed". With his consciousness thus raised, Ehlers initiated an aerial photographic survey of the Wichter Ee, a tidal inlet between the barrier islands of Norderney and Baltrum, over a 30-day period. The resulting analysis of shoal and megaripple migration forms the core of this book, but there is much more.

After chapters on barrier-island development, recent geomorphological processes, morphodynamic units and historical development, the author rolls up his sleeves and launches into a description, one by one, of the 35 barrier islands of the Wadden Sea and their associated intertidal terrains. This roll call of islands, from Fan $\varnothing$, Mand $\varnothing, \mathrm{R} \emptyset \mathrm{m} \emptyset$ and Sylt in the North Frisian Islands, through Wangerooge, Spiekerooge, Langeooge and Baltrum in the East Frisian chain, to Terschelling, Griend, Vlieland and Texel in the West Frisian Islands, will for many readers constitute the real strength of the book.

The careful review of historical records is another valuable contribution. Eight centuries of documents allow us to shift from the time scale of fluid dynamical processes at seconds, minutes, days and years into the lower portion of the geological frequency band. Within these eight centuries we can resolve some of the event-dominated fine structure of the most recent phase of the Holocene transgression of the North Sea basin. Important loss of land occurred in the storm surges of the years $1010,1020,1041,1075$, $1094,1102,1114,1164$ and 1282. The greatest single land loss resulted from the surge of 16 January, 1362, the second Marcellus flood, also known as the Grosse Mandränke (great mandrowning). Jade Bay, the Dollart and Harle Bay were enlarged, and in Nordfriesland vast areas of land disappeared under water, including the legendary Rungholt, east of the present island of Pellworm. A second Mandränke occurred on 11 October, 1694. But the main and partially enduring land losses, resulting in the formation of Jade Bay, the Dollart and the Zuider Zee, did not occur as the result of single events, but gradually, through many smaller stages. These land losses were due to a lack of technical infrastructure capable of protecting the vast forelands from the destructive effects of later surges in later decades. Land reclamation occurred, but only through projects that lasted for centuries.

It is important to appreciate this monograph for the fine work of descriptive morphodynamics that it is, and to avoid

\section{Nature explained}

\section{R. McNeill Alexander}

Life's Devices: The Physical World of Animals and Plants. By Steven Vogel. Princeton University Press:1988. Pp.367. Hbk \$49.50; pbk \$17.95.

Why do starfish have five arms? Why don't animals run on wheels? And isn't it intriguing that spider silk has five times the strength of mild steel, and that prairie dogs (rodents, not canines) dig self-ventilating burrows? Here is a brilliant and eccentric book that looks at living things from an engineering point of view, assuming astonishingly little previous knowledge of science on the reader's part.

A summary of one chapter will give the flavour of the whole. Under the same weight of laundry, a sagging clothes line is less likely to break than a tight one. This helps us to understand why there is more tension in the wall of a large pipe than of a smaller one, when both contain fluid at the same pressure: automobile tyres need thicker walls than bicycle tyres (although the latter are inflated to higher pressure), and arteries need thicker walls than blood capillaries. Toy balloons do not inflate uniformly but start with a localized bulge, and blood vessels would be apt to swell similarly were it not for the peculiar properties of their walls. Our lungs need an internal coating of a wetting agent to make their 30 million tiny pockets (alveoli) swell uniformly when we breathe in; which leads to an explanation of why bubbles form against the wall of a beer glass, not in mid-beer.

Professor Vogel suggests two uses for his book: as the basis of a course for nonscientists in liberal studies programmes or, for biologists, as a preparation for deeper biomechanical studies and more advanced reading. Life's Devices will be excellent in either role. It is organized by viewing it as an indifferently designed work of other purpose. The author's skills lie in the collecting and ordering of information. Chapters that attempt to take an overview, such as those on natural preconditions and barrier-island development, are not altogether successful, although they are always interesting. On the other hand, the relentless procession of maps, aerial photographs and, above all, photograph after photograph at ground level, has a hypnotic effect. Somewhere through the 393 figures, these vistas of misty dunes, beaches and marshes, and of tidal flats extending to the horizon, seep into the unconscious - you have been there.

Donald J.P. Swift is a Professor in the Department of Oceanography, Old Dominion University, Norfolk, Virginia 23529, USA.

physical topics: dimensions and scaling principles first, then fluid mechanics, properties of materials, structures and mechanisms. All the mechanics is introduced simply, including tricky topics such as the bending of beams. There are no logarithms or trigonometrical functions, and there is even an appendix as a reminder of how equations work. No background in science is necessary to enjoy the book, only intelligence and the willingness to stop and think.

Here are a great many fascinating scientific stories, including quite a lot that I did not previously know. Too often, though, the explanations are frustratingly short. I doubt whether naïve readers will get a clear understanding of the plastron of aquatic insects, which enables them to breathe under water, from this brief, unillustrated account. I doubt whether they will appreciate the strange properties of slug slime, which enables slugs to crawl while keeping the whole area of the foot perpetually on the ground; as the slug crawls the slime under each part of its foot behaves alternately like a rubbery solid (giving the slug a purchase on the ground) and like a viscous liquid (letting it slide forward). The sparkle of the book depends on its pace, but there were times when it would better have been slowed down.

Professor Vogel is a distinguished biologist who has discovered many revealing things about the flow of water and air over animals and plants. He is also the author of a more advanced biomechanics book, Life in Moving Fluids, published by Willard Grant, Boston, in 1981. In an aside half way through his new book he tells us the secret of his success, which is also the book's philosophy: "A good way to make a neat discovery is to begin, not with your favorite organism, but with some physical property or phenomenon and then ask how animals might take advantage of it".

R. MCNeill Alexander is a Professor in the Department of Pure and Applied Biology, University of Leeds, Leeds LS2 9JT, UK. 